\title{
Conhecimento dos enfermeiros sobre o novo código de ética do profissional de enfermagem
}

RESUMO | Com a recente atualização do Código de Ética dos Profissionais de Enfermagem, essa tornou-se conhecida apenas por parte dos profissionais. Objetivo: avaliar o conhecimento dos enfermeiros sobre o Código de Ética dos Profissionais de Enfermagem. Método: Trata-se de um estudo observacional, descritivo e transversal, com dados coletados no período de setembro a outubro de 2018, por meio de um questionário online, via Plataforma Google Forms $®$. Participaram da pesquisa 217 enfermeiros, sendo 190 (87,46\%) do sexo feminino e 27 (12,44\%) do sexo masculino. Resultado: Em relação aos direitos, os participantes obtiveram respostas semelhantes, considerando a alternativa mais coerente. Quanto aos deveres e proibições, apresentaram grande diversidade e discordância entre as alternativas escolhidas, demonstrando dúvida ou equívoco por parte dos participantes. Conclusão: Foi possível observar que o conhecimento dos enfermeiros acerca do Código de Ética Profissional de Enfermagem é limitado em relação aos deveres e proibições da profissão.

Palavras-chaves: Códigos de Ética; Enfermeiro; Ética em Enfermagem; Conhecimento; Comunicação.

\begin{abstract}
With the recent update of the Nursing Professionals Code of Ethics, this became known only by professionals. Objective: to evaluate nurses' knowledge of the Nursing Professionals Code of Ethics. Method: This is an observational, descriptive and cross-sectional study, with data collected from September to October 2018, through an online questionnaire, via the Google Forms@ Platform. 217 nurses participated in the research, 190 (87.46\%) female and $27(12.44 \%)$ male. Result: Regarding rights, the participants obtained similar responses, considering the most coherent alternative. As for duties and prohibitions, they showed great diversity and disagreement between the alternatives chosen, showing doubt or misunderstanding on the part of the participants. Conclusion: It was possible to observe that the nurses' knowledge about the Nursing Professional Code of Ethics is limited in relation to the duties and prohibitions of the profession.
\end{abstract}

Keywords: Codes of Ethics; Nurse; Nursing Ethics; Knowledge; Communication.

RESUMEN | Con la reciente actualización del Código de Ética de los Profesionales de Enfermería, esto solo se dio a conocer por los profesionales. Objetivo: evaluar el conocimiento de los enfermeros sobre el Código de Ética para Profesionales de Enfermería. Método: Se trata de un estudio observacional, descriptivo y transversal, con datos recolectados de septiembre a octubre de 2018, a través de un cuestionario en línea, vía Google Forms® Platform. En la investigación participaron 217 enfermeras, 190 (87,46\%) mujeres y 27 $(12,44 \%)$ hombres. Resultado: En cuanto a derechos, los participantes obtuvieron respuestas similares, considerando la alternativa más coherente. En cuanto a deberes y prohibiciones, mostraron gran diversidad y desacuerdo entre las alternativas elegidas, mostrando dudas o incomprensiones por parte de los participantes. Conclusión: se pudo observar que el conocimiento de las enfermeras sobre el Código de Ética Profesional de Enfermería es limitado en relación a los deberes y prohibiciones de la profesión.

Palabras claves: Códigos de Ética; Enfermera; Ética en enfermería; Conocimiento; Comunicación.

\section{Laryssa Gaston Becker}

Enfermeira no Hospital Santa Casa de Misericórdia de Porto Alegre.

ORCID: 0000-0001-7193-9363

\section{Elisa Kowalski Kologesi do Nascimento}

Acadêmica de enfermagem do Centro Universitário Ritter dos Reis (UniRitter). Estagiária do Controle de Infecção Hospitalar do Hospital Nossa Senhora da Conceição em Porto Alegre- RS.

ORCID: 0000-0003-4015-615X

\section{Nathália Torres Mendes}

Enfermeira assistencial no Hospital Pronto Socorro de Canoas (HPSC). Pós-graduanda em UTI geral e gestão da assistência intensiva ao paciente crítico pela Faculdade Dom Alberto.

ORCID: 0000-0002-2321-818X

Recebido em: 19/07/2020

Aprovado em: 28/07/2020

\section{Amanda Pereira Ferreira Dellanhese}

Gerente das Unidades de Saúde Herdeiros e Esmeralda. Gerência Distrital Partenon, Lomba do Pinheiro da APS Hospital Divina Providência, Porto Alegre-RS. Doutora em Saúde da Criança e do Adolescente pela Universidade Federal do Rio Grande do Sul. Docente Colaboradora da Residência Integrada Multiprofissional em Saúde Coletiva da Universidade Federal do Rio Grande do Sul. ORCID: 0000-0002-1515-9693

\section{Simone Lysakowski}

Doutoranda em Pediatria pela Universidade Federal de Ciências da Saúde de Porto Alegre (UFCSPA). Mestre em Ensino na Saúde pela UFCSPA. Especialista em Docência no Ensino Superior pela Pontifícia Universidade Católica do Rio Grande do Sul (PUCRS). Especialista em Doação e Transplantes e em Oncologia pela Universidade São Camilo. Enfermeira na Organização de Procura de Órgãos (OPO 1) na Santa Casa de Misericórdia de Porto Alegre. ORCID: 0000-0003-3959-956X

\section{Morgana Thais Carollo Fernandes}

Enfermeira. Pós-Doutoranda em Saúde da Criança pela Pontifícia Universidade Católica do Rio Grande do Sul (PUCRS), bolsista pela University of Toronto (UofT). Professora Colaboradora da Residência Multiprofissional em Saúde da Criança e Pesquisadora Associada do Programa de Extensão e Pesquisa em Saúde Urbana, Ambiente e Desigualdades da Universidade Federal do Rio Grande do Sul (UFRGS). ORCID: 0000-0002-7989-294X

INTRODUÇÃO

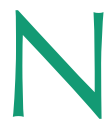
a assistência à saúde o enfermeiro se envolve com aspectos gerenciais, de liderança e de cuidado direto aos pacientes, sendo muitas vezes necessária a tomada de decisões, de forma rápida e justa, mediando conflitos e atendendo a situações de violência e vulnerabilidade, que po- 
dem muitas vezes levá-lo a questionar suas condutas éticas. ${ }^{(1)}$ Para garantir a assistência de forma benevolente, a ética profissional se faz aliada, uma vez que, os profissionais da saúde têm o dever de realizar suas ações balizadas em seus próprios valores, juntamente aos princípios institucionais, bem como o direito de recusar-se a executar tarefas que não sejam de sua competência técnica, ética e legal, ou que não ofereçam segurança ao profissional, ao paciente, à família e à coletividade. $^{(2)}$

De forma a garantir a qualidade dos serviços prestados e o cumprimento da Lei do Exercício Profissional, o ConseIho Federal de Enfermagem (COFEN) é responsável por normatizar e fiscalizar o exercício da profissão de enfermeiros, técnicos e auxiliares de enfermagem, bem como obstetrizes e parteiras, atuando juntamente com os Conselhos Regionais de Enfermagem (COREN). ${ }^{(2)}$ O Código de Ética dos Profissionais de Enfermagem (CEPE), aprovado pelo COFEN, é o documento que regulamenta a profissão, tendo como objetivo nortear o processo de trabalho. ${ }^{(2)} \mathrm{A}$ importância do conhecimento do CEPE é representada pelo quantitativo de profissionais dispersos pelo Brasil, que somam 417.519 auxiliares, 1.307.680 técnicos, 558.318 enfermeiros e 291 obstetrizes, totalizando 2.283.808 profissionais registrados no respectivo conselho de enfermagem até março de 2020. ${ }^{(3)}$

Em 2017 o COFEN publicou o novo CEPE, tendo antes disso, outras três edições, nos anos de 1993, 2000 e 2007. (2) A recente versão apresenta uma linguagem mais clara e objetiva na deliberação dos direitos, deveres, proibições e penalidades ao profissional da enfermagem vinculado ao conselho. ${ }^{(2,4)}$ Apesar de campanhas, cursos e seminários para a propagação do CEPE, percebe-se que ainda é pouco explorado pelos profissionais, sugerindo a carência do tema desde a graduação até os anos subsequentes à formação. ${ }^{(4-6)}$

A abordagem da ética profissional,
Percebemos a necessidade de os enfermeiros possuírem conhecimento em relação ao CEPE, sendo essencial para garantia da qualidade dos serviços prestados, seguindo os princípios da ética e da bioética, além de assegurar a universalidade de acesso, integralidade da assistência, resolutividade, preservação da autonomia das pessoas, considerados estes princípios fundamentais. não segue o contexto das necessidades da sociedade, sendo comum que disciplinas voltadas para o tema sejam abordadas em cadeiras optativas ou em seminários multidisciplinares. Talvez isso ocorra, quando os líderes e coordenadores, responsáveis pela formação dos novos profissionais, não compreendem a importância de embasar o conhecimento e a prática sobre a ética em enfermagem. ${ }^{(7,8)}$

Estudo realizado em 2017 identificou divergências entre os participantes quanto ao significado de ética, estando sua compreensão, por vezes, relacionada às experiências e aspectos pessoais, e não perante o coletivo. ${ }^{(4)}$ Outra pesquisa realizada em 2018 com 11 enfermeiros, evidenciou que mais da metade dos entrevistados desconheciam os princípios fundamentais descritos pelo código de ética. ${ }^{(5)}$

A enfermagem permanece dentre as profissões da saúde como aquela com grande quantitativo de recursos humanos, e que permanece 24 horas ao laudo do seu paciete. Sendo assim, a ética nesse contexto assistencial mostra-se com o intuito de prover o respeito ao próximo em todos seus aspectos, auxiliando e desenvolvendo o equilíbrio e a condição humana no processo de adoecimento, cura, invalidez ou morte..$^{(9)}$

Com base na realidade de atuação diária dos enfermeiros os conflitos éticos tornam-se inevitáveis, e diante disso a reflexão sobre esses embates laborais devem objetivos e claros aos profissionais, tendo como base filosófica a legislação do referido conselho, a fim de preservar a autonomia dos enfermeiros sem causar qualquer tipo de malefício ao próximo. ${ }^{(9)}$

Percebemos a necessidade de os enfermeiros possuírem conhecimento em relação ao CEPE, sendo essencial para garantia da qualidade dos serviços prestados, seguindo os princípios da ética e da bioética, além de assegurar a universalidade de acesso, integralidade da assistência, resolutividade, preservação da autonomia das pessoas, considerados estes princípios fundamentais. ${ }^{(2)}$ 
Com base nisso, o estudo objetivou identificar o conhecimento dos enfermeiros sobre o novo Código de Ética dos Profissionais de Enfermagem referentes aos direitos, deveres e proibições, bem como os dados sociodemográficos dos participantes.

\section{MÉTODOS}

Trata-se de um estudo observacional descritivo, transversal que consiste na aplicação de técnicas padronizadas de coleta de dados, tais como o questionário e a observação sistemática, tendo como objetivo descrever determinada população ou fenômeno. ${ }^{(10)}$ A coleta de dados foi realizada por conveniência no período de setembro a outubro de 2018, por meio de questionário online, preenchido via Plataforma do Google Forms ${ }^{\circledR}$, composto por vinte questões fechadas baseadas no CEPE, envolvendo dados sociodemográficos e de conhecimento específico acerca dos direitos, deveres e proibições profissionais. A divulgação do questionário se deu por compartilhamento em redes sociais e por meio de endereço eletrônico (e-mail). A plataforma online oportunizou que o questionário fosse preenchido por profissionais das mais diversas regiões brasileiras.

Os critérios de inclusão foram enfermeiros com registro ativo no conselho regional de enfermagem, residentes no Brasil. Exclui-se outros profissionais da saúde e/ou da enfermagem bem como participantes que se recusaram a aceitar o Termo de Consentimento Livre e Esclarecido (TCLE). Aos profissionais que demonstraram interesse em participar da pesquisa, fora encaminhado por e-mail o TCLE. Daqueles que tivemos o retorno preenchido, se deu início a coleta de dados.

O tamanho amostral foi determinado a partir da população total de 496.055 enfermeiros cadastrados nos CORENs em 2018. ${ }^{(3)}$ A partir disso, determinou-se a necessidade de 217 participante no estudo, com margem de erro de $5 \%$ e intervalo de confiança de $95 \%$. ${ }^{(11)}$ Foi realizado um piloto com dez enfermeiros e, em seguida os dados foram descartados, após análise de possíveis melhorias.

Os dados coletados serão armazena-

Tabela 1. Caracterização sociodemográfica dos participantes. Brasil, 2018.

\begin{tabular}{|lcccc|}
\multicolumn{1}{c}{ Variáveis } & \multicolumn{2}{c}{ Feminino } & \multicolumn{2}{c}{ Masculino } \\
\hline Tempo de formação & $\mathbf{n}$ & $\%$ & $\mathbf{n}$ & $\%$ \\
\hline De 0 a 2 anos & & & 13 & 5,99 \\
\hline De 3 a 5 anos & 42 & 19,35 & 4 & 1,84 \\
\hline De 6 a 10 anos & 35 & 16,13 & 5 & 2,30 \\
\hline De 11 a 15 anos & 39 & 17,97 & 4 & 1,84 \\
\hline Mais de 15 anos & 26 & 11,98 & 1 & 0,46 \\
\hline Tempo de atuação profissional & 48 & 22,12 & 17 & 7,83 \\
\hline De 0 a 2 anos & & & 5 & 2,30 \\
\hline De 6 a 10 anos & 58 & 26,73 & 1 & 0,46 \\
\hline Mais de 15 anos & 40 & 18,43 & 2 & 0,92 \\
\hline De 3 a 5 anos & 43 & 19,82 & 2 & 0,92 \\
\hline De 11 a 15 anos & 25 & 11,52 & & \\
\hline Maior titulação concluída & 24 & 11,06 & 16 & 7,37 \\
\hline Graduação & & & 6 & 2,76 \\
\hline Especialização & 65 & 29,95 & 46,08 & \\
\hline
\end{tabular}

dos por cinco anos no banco de dados Excel ${ }^{\circledR}$ e após este prazo, excluídos permanentemente da rede. Os dados foram tabulados no Programa Excel, expressos em frequências absoluta e relativa.

A pesquisa seguiu os critérios estabelecidos pela Resolução 466/2.012 do Conselho Nacional de Saúde (CNS), para pesquisas envolvendo seres humanos, sendo aprovado pela Comissão de Ética em Pesquisa (CEP) do Centro Universitário Ritter dos Reis, sob parecer consubstanciado $n^{\circ}$ 2880947, CAAE 9526.4418.7.0000.5309. Os pesquisadores envolvidos tiveram compromisso com a privacidade e a confidencialidade e os dados utilizados foram preservados. ${ }^{(12)}$

\section{RESULTADOS}

Participaram da pesquisa 217 enfermeiros, sendo $190(87,46 \%)$ do sexo feminino e $27(12,44 \%)$ do sexo masculino. Importante parcela possuía título de especialista 106 (48,85\%) e tempo de formação entre 0 a 2 anos 55 (25,34\%) seguido de mais de 15 anos 49 (22,58\%) e 6 a 10 anos 44 (20,27\%). O setor de atuação mais citado foi à atenção secundária 69 (31,8\%) e o estado de maior participação foi o Rio Grande do Sul (RS) com 190 (87,56\%) participantes (Tabela 1$)$.

Quanto aos conhecimentos específicos sobre os direitos profissionais, 148 $(68,20 \%)$ acreditam que as atividades individuais e coletivas devem ser suspensas quando o local de trabalho não oferecer condições seguras para o exercício profissional e/ou desrespeitar a legislação vigente, salvo em situações de urgência e emergência. Em relação a recusa de registros fotográficos e filmagens durante o trabalho, mesmo que seja uma solicitação institucional, 205 (94,47\%) afirmaram possuir o direito de negar-se a exposição. Por fim, 210 (96,77\%) pressupõem o direito de recusa na administração de medicações ou realização de procedimentos que não ofereçam segurança ao profissional, à pessoa, à família e à coletividade (Tabela 2). 


\begin{tabular}{|lcccc|}
\hline Mestrado & 17 & 7,83 & 4 & 1,84 \\
\hline Doutorado & 6 & 2,76 & 1 & 0,46 \\
\hline Pós-doutorado & 2 & 0,92 & - & - \\
\hline Setor de Atuação* & & & & \\
\hline Atenção primária & 48 & 22,12 & 8 & 3,69 \\
\hline Atenção secundária & 59 & 27,19 & 10 & 4,61 \\
\hline Atenção terciária & 41 & 18,89 & 4 & 1,84 \\
\hline Docência / Pesquisa & 27 & 12,44 & 5 & 2,30 \\
\hline Gestão & 7 & 3,23 & & \\
\hline Outros* * & 8 & 3,69 & & \\
\hline
\end{tabular}

Fonte: elaborada pelos autores. Legenda: *considerada o emprego com maior carga horária de atuação profissional. **outros: vigilância epidemiológica, farmácia, comércio ou não está atuando no momento.

Tabela 2. Conhecimentos específicos sobre os direitos dos enfermeiros. Brasil, 2018.

Variáveis

Suspensão do trabalho em condições de risco

\begin{tabular}{lccc}
\hline Deve ser suspenso, exceto em situações de urgência e emergência & 148 & 68,20 \\
\hline Deve ser suspenso em qualquer situação & 42 & 19,35 \\
\hline Deve-se garantir a continuidade da assistência & 16 & 7,37 \\
\hline Não souberam opinar & 11 & 5,07 \\
\hline Direito de recusa a registros fotográficos durante atuação & & \\
\hline Sim & 205 & 94,47 \\
\hline Não & 7 & 3,23 \\
\hline Não souberam opinar & 5 & 2,30
\end{tabular}

Direito de recusa na administração de medicações/procedimentos em condições de risco

\begin{tabular}{|c|c|c|}
\hline Sim & 210 & 96,77 \\
\hline Não souberam opinar & 3 & 1,38 \\
\hline Não & 3 & 1,38 \\
\hline Não, se o médico ou a instituição solicitar, é obrigatório executar & 1 & 0,46 \\
\hline
\end{tabular}

Tabela 3. Conhecimentos específicos dos enfermeiros sobre deveres e proibições segundo o código de ética profissional da enfermagem. Brasil, 2018.

Variáveis

n $\%$

Identificação documental

Nome completo, categoria de inscrição e número do COREN* em carimbo e assinatura/rubrica

\begin{tabular}{lcc}
\hline Nome completo, categoria de inscrição e número do COREN, assinatura/rubrica & 36 & 16,59 \\
\hline Apenas o nome completo e assinatura/rubrica & 1 & 0,46 \\
\hline Nome completo, assinatura/rubrica e cargo & 1 & 0,46
\end{tabular}

Quebra do sigilo profissional em situações de violência

Comunicar imediatamente os órgãos envolvidos

$177 \quad 81,57$

Manutenção do sigilo

$24 \quad 11,06$

Ao serem questionados sobre os deveres e proibições profissionais, 179 $(82,49 \%)$ responderam que os documentos institucionais devem conter nome completo, categoria de inscrição, número do registro profissional em carimbo e assinatura/rubrica. Quanto ao sigilo profissional em situações de violência, $177(81,57 \%)$ acreditam que deve ser quebrado devendo-se obrigatoriamente comunicar os órgãos de responsabilização criminal.

Em relação às orientações obrigatórias durante a assistência, 125 (57,60\%) afirmaram ser obrigatório informar sobre riscos, benefícios, intercorrências e direitos de recusa e 29 (13,36\%) somente riscos e benefícios. Nos casos de doenças graves incuráveis e terminais, com risco iminente de morte, em comum acordo com a equipe multiprofissional, 196 $(90,32 \%)$ assegurariam o conforto físico, psíquico e espiritual, respeitando a vontade do paciente ou seu representante legal e $20(9,22 \%)$ acreditam que se deve preservar a vida, usufruindo de todo suporte avançado mesmo sem consentimento da pessoa ou de seu representante legal.

Tratando-se de fazer referência a casos, situações ou fatos e inserir imagens de pessoas ou instituições em meio de comunicações, 128 (58,99\%) enfermeiros responderam que é permitido, desde que haja autorização prévia, 71 (32,72\%) pressupõem que é terminantemente proibido e 12 (5,53\%) afirmaram que sim, desde que os envolvidos não sejam identificados. Acerca da delegação das atividades privativas do enfermeiro, 89 $(41,01 \%)$ acreditam que é proibido em qualquer situação, 85 (39,17\%) proibido, exceto nos casos de emergência e atenção domiciliar para autocuidado apoiado e $36(16,59 \%)$ permitiriam desde que estivessem do lado de quem fosse executar a ação (Tabela 3).

\section{DISCUSSÃO}

Os achados vão ao encontro de estudos anteriores semelhantes, que também 


\begin{tabular}{|ccc|}
\hline Decisão a critério do profissional & 11 & 5,07 \\
\hline Não souberam opinar & 5 & 2,30 \\
\hline Orientações durante a assistência & & \\
\hline Riscos, benefícios, intercorrências e direito de recusa & 125 & 57,60 \\
\hline Riscos e benefícios & 29 & 13,36 \\
\hline Riscos, benefícios e direito de recusa & 18 & 8,29 \\
\hline Riscos, benefícios e intercorrências & 12 & 5,53 \\
\hline Direito de recusa & 11 & 5,07 \\
\hline Riscos, benefícios, intercorrências, direito de recusa e custos para a instituição & 9 & 4,15 \\
\hline Outros* & 12 & 5,52 \\
\hline Não souberam opinar & 1 & 0,46 \\
\hline
\end{tabular}

Conduta em casos de doenças graves incuráveis e terminais***

Conforto físico, psíquico, social e espiritual, respeitada a vontade da pessoa ou de seu representante legal

19690,32

Preservação da vida, usufruindo de todo suporte avançado de vida***

$20 \quad 9,22$

Não souberam opinar

10,46

Uso de imagens de pessoas ou instituições em meios de comunicações

\begin{tabular}{lcc} 
Sim, desde que haja autorização prévia & 128 & 58,99 \\
\hline Não, é terminantemente proibido & 71 & 32,72 \\
\hline Sim, desde que não sejam identificados & 12 & 5,53 \\
\hline Não souberam opinar & 5 & 2,30 \\
\hline Sim, desde que não sejam identificados, ou haja autorização prévia & 1 & 0,46 \\
\hline $\begin{array}{l}\text { Delegação das atividades privativas do enfermeiro } \\
\text { Proibido em qualquer situação }\end{array}$ & 89 & 41,01 \\
\hline $\begin{array}{l}\text { Proibido, exceto nos casos de emergência e atenção domiciliar para autocuidado } \\
\text { apoiado }\end{array}$ & 85 & 39,17 \\
\hline É permitido desde que o enfermeiro esteja ao lado de quem for executar & 36 & 16,59 \\
\hline Não souberam opinar & 7 & 3,23
\end{tabular}

Fonte: elaborado pelos autores. Legenda: *COREN: Conselho Regional de Enfermagem. **orientações durante a assistência: outros (intercorrências, custos para a instituição, direito de recusa e intercorrências); *** conduta considerada em casos de doenças graves, incuráveis e terminais com risco iminente de morte, em comum acordo com a equipe multiprofissional; *** preservação da vida, usufruindo de todo suporte avançado de vida considerado mesmo sem consentimento da pessoa ou de seu representante legal.

constataram a maior participação do gênero feminino com $91,67 \%$ e $92,6 \%$, respectivamente. ${ }^{(6,4)}$ Tal dado corrobora com a pesquisa do perfil da enfermagem no Brasil, realizada pelo COFEN em 2013, que mostra o predomínio de enfermeiros do gênero feminino $86,2 \%$ e a maioria dos participantes com título de especialista, representando $72,8 \%$ ). ${ }^{(13)}$

Quanto aos conhecimentos específicos em relação aos diretos dos enfermeiros, $148(68,20 \%)$ participantes acreditam que tenham direito de suspender as ativi- dades individuais ou coletivas, quando o local de trabalho não oferecer condições seguras, ressalvas situações de urgência e emergência. O CEPE descreve, que de fato os profissionais podem suspender o processo de trabalho, quando este não oferecer condições seguras, ressalva situações de urgência e emergência. ${ }^{2)}$

Apesar disso, 42 (19,35\%) pressupõem que a assistência deve ser suspensa em qualquer situação e 16 (7,37\%) dariam continuidade, independentemente da situação de risco. Ressalta-se que aproximadamente 139 mil enfermeiros brasileiros já sofreram algum tipo de violência no ambiente de trabalho do tipo psicológica (113 mil), institucional (41 mil), física (15 mil) e sexual $(1 \mathrm{mil}){ }^{(13)} \mathrm{Es}-$ tudo anterior com a mesma abordagem constatou que a maioria dos respondentes, $13(72,22 \%)$, possuía conhecimento sobre seus direitos de suspensão das atividades. ${ }^{(5)}$ Esse resultado estratifica a importância de falar mais sobre direitos e deveres dos profissionais da enfermagem, que só conseguirão prestar uma assistência de qualidade quando souberem o que rege o CEPE.

Tal achado, quanto a realização da assistência independente dos riscos, se faz necessária nos dias atuais, quando se vive uma pandemia e a enfermagem está vendo seus profissionais infectados e mortos, tendo muitas vezes como motivo, a falta de equipamentos de proteção, a insegurança e o medo de expor a situações aos responsáveis. ${ }^{(14)}$

Dos 217 participantes, 205 (94,97\%) afirmaram ter direito a recusar registros fotográficos durante atuação profissional. De acordo com estudo de Pereira (2006), caso o empregador utilize imagens para marketing, sem autorização prévia ou utilizando além do que foi autorizado o empregado pode receber indenização por danos morais e materiais. ${ }^{(15)}$ Essa informação é muito relevante, ao constatar que estamos inseridos em uma era digital e diversas questões éticas acabam por serem infringidas pelo desconhecimento das mesmas.

Sobre o uso de imagens de pessoas ou instituições em meios de comunicação, 128 (58,99\%) responderam que pode ser publicado, desde que haja autorização prévia e 71 (32,72\%) pressupõem que seja terminantemente proibido. A resolução do COFEN No 554/2017 expressa que é vedado ao profissional de enfermagem expor nome, fotografias, face, corpo ou imagens de exames em redes sociais, que não se destinem a atividades acadêmicas sem a expressa autorização dos pacientes. ${ }^{(16-18)}$ 
De forma positiva, quanto a administração de medicamentos e realização de procedimentos em condições de risco, $210(96,77 \%)$ afirmaram possuírem o direito de recusa, indo ao encontro da recomendação do CEPE.(2) Compreender os padrões de segurança relativos ao processo de administração de medicamentos, e saber identificar possíveis erros a tempo de evita-los, é uma ação do enfermeiro como gestor do cuidado, uma vez que é um dos processos em que há a maior participação da equipe de enfermagem. ${ }^{(19,20)}$

Outro dever da enfermagem, de extrema importância, é a identificação profissional após os registros realizados no prontuário do paciente, visto que, este é considerado um documento legal de defesa dos profissionais e pacientes, devendo, portanto, estar imbuídos de autenticidade e de significado legal. Dessa forma, para serem considerados válidos devem estar legalmente identificados, possuir assinatura do autor do registro ou rubrica, acompanhados de carimbo com a sigla do COREN, unidade federativa, seguido do número de inscrição e sigla da categoria profissional de enfermagem, separados por hífen. ${ }^{(21)}$ Dos 217 enfermeiros participantes, 179 (82,49\%) informaram que realizam a identificação documental conforme preconizado pelo CEPE.

Em relação ao sigilo profissional, a maioria dos participantes 177 (81,57\%) acreditam que em situações de violência, este não deve ser mantido devendo-se obrigatoriamente comunicar os órgãos de responsabilização criminal, reforçando a deliberação do CEPE. ${ }^{(2)}$ Apesar disso, 24 $(11,06 \%)$ enfermeiros manteriam o sigilo. Ressalta-se que a obrigatoriedade de quebra de sigilo nessas situações é tanto ética quanto legal. . $^{(1,16)}$

O CEPE aborda ainda a questão dos casos de doenças graves incuráveis e terminais com risco iminente de morte. Sobre esse tema, em comum acordo com a equipe multiprofissional, a maioria dos enfermeiros 196 (90,32\%) concordam com o preconizado, que é assegurar o conforto físico, psíquico e espiritual, respeitando a vontade do paciente ou seu representante legal. Assim, a enfermagem pode apoiar o enfermo e sua família, minimizando seus medos e ansiedades, devendo ser capaz de identificar desordens físicas, psíquicas, sociais e espirituais. ${ }^{(22)}$ Além do CEPE, a Organização Mundial da Saúde (OMS) (2002) aponta como princípios dos cuidados paliativos, promover o alívio da dor e outros sintomas estressantes, além de não pretender antecipar e nem postergar a morte, enxergando a morte como um processo natural. ${ }^{(23,24)}$

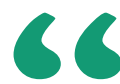

Em relação ao sigilo profissional, a maioria dos participantes 177 $(81,57 \%)$ acreditam que em situações de violência, este não deve ser mantido devendose obrigatoriamente comunicar os órgãos de responsabilização criminal, reforçando a deliberação do CEPE.

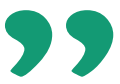

Estudo realizado com discentes, referente ao ensino sobre terminalidade da vida, durante a graduação em enfermagem, mostrou o despreparo e o medo dos alunos para falar no assunto, expondo a necessidade de um trabalho contínuo e projetado para retomar, durante toda a formação, as situações de morte e luto. Isso evidencia a necessidade de formação dos profissionais, tornando-os embasados e confortáveis para atuar diante da morte, respeitando os direitos e autonomia dos pacientes. ${ }^{(25)}$

Durante a execução de algum procedimento ou exame 125 (57,6\%) dos entrevistados informaram que orientam sobre riscos, benefícios, intercorrências e o direito de recusa do paciente. O CEPE menciona o dever da enfermagem em orientar a pessoa e a família sobre todo o processo da assistência de enfermagem bem como procedimentos e exames. ${ }^{(2)}$

Sobre a delegação de atividades privativas do enfermeiro, houve divergências de opiniões entre os participantes, a maior parte 89 (41,01\%) entende que é proibido em qualquer situação delegar, entretanto, 85 (39,17\%) pressupõem ser proibido, exceto em casos de emergência e de atenção domiciliar para o autocuidado apoiado. A resolução COFEN 564/2017 determina a proibição da delegação de atividades privativas do enfermeiro para outro membro da equipe de enfermagem, porém de fato o CEPE não pune em casos de atenção domiciliar para o autocuidado apoiado.(2)

As limitações neste estudo são decorrentes do uso de questionário online, como memória e confundimento. ${ }^{(26)}$ Ademais, sugere-se que a falta de reflexão continuada sobre o tema pelos enfermeiros apresenta-se como limitação, uma vez que conforme pesquisas anteriores a ética profissional é abordada somente durante a formação nas universidades e superficialmente sem preconizar os temas transversais. Os potenciais vieses decorrentes dessas limitações são reconhecíveis ainda que seja possível obter um panorama do conhecimento dos enfermeiros sobre o CEPE de modo considerável. 
CONCLUSÃO

A partir dos resultados foi possível observar que o conhecimento dos enfermeiros acerca do Código de Ética dos Profissionais de Enfermagem é limitado, principalmente em relação aos deveres e proibições profissionais, que são aspectos extremamente importantes para manutenção da qualidade assistencial. Identificou-se na pesquisa que os participantes possuem amplitude de conhecimento sobre seus direitos, enquanto seus deveres e proibições obtiveram baixo índice de consenso entre os enfermeiros, sendo fundamentais para o exercício da profissão. Entende-se ser necessário que os enfermeiros se empoderem do seu código de ética, reconhecendo assim as questões nele descritas, a fim de garantir segurança para si e a autonomia dos sujeitos por ele cuidado, sem interferir nos aspectos éticos da prática profissional.

Espera-se que por meio deste estudo que novas pesquisas sejam realizadas a fim de avaliar formatos de ensino a esses profissionais, propiciando assim maio conhecimento frente ao Código de Ética dos Profissionais de Enfermagem. Ainda, deve-se destacar a necessidade de discutir esse assunto na academia, investindo na formação dos profissionais.

\section{Referências}

1. Peres AM, Ciampone MH. Gerência e competências gerais do enfermeiro. Texto Contexto Enferm. 2006;15(3):492-9.

2. Conselho Federal de Enfermagem (COFEN). Resolução COFEN n. 564, de 6 de novembro de 2017. Aprova o novo Código de Ética dos Profissionais de Enfermagem [Internet]. Brasília (DF): COFEN; 2017 [citado em 22 de Março de 2018]. Disponível em: http://www.cofen.gov.br/resolucao-cofen-no-5642017_59145.html 3. Conselho Federal de Enfermagem (COFEN). Enfermagem em números [Internet]. Brasília (DF): COFEN; 2020 [citado em 15 de Abril de 2020]. Disponível em: http://www.cofen.gov.br/enfermagem-em-numeros.

4. Barbosa ML, Rodrigues HN, Celino SD, Costa GM. Conhecimento de profissionais de enfermagem sobre o código de ética que rege a profissão. Rev baiana enferm. 2017;31(4):e21978.

5. de Araújo DY, de Araújo ÉJ, Barros Ide C. 0 conhecimento dos enfermeiros do município de Teresina/PI sobre seu código de ética. Vita Sanitas. 2011;5(1):34-50. 6. Ferraz C, Magnabosco P. Conhecimento e percepção dos profissionais de enfermagem sobre o código de ética da profissão, 2011. [citado em 23 de Março de 2020]. Disponível em: http://certificados-cbcenf.cofen.gov.br/sistemainscricoes/ anais.php?evt $=9 \& \mathrm{sec}=48 \& \mathrm{Riv}=7.1 \& \mathrm{mod}=1 \& \mathrm{con}=5286$.

7. Souza ML, Sartor VV, Prado ML. Subsídios para uma ética da responsabilidade em enfermagem. Texto Contexto Enferm. 2005;14(1):75-81.

8. Dantas F, Sousa EG. Ensino da deontologia, ética médica e bioética nas escolas médicas Brasileiras: uma revisão sistemática. Rev Bras Educ Med. 2008;32(4):507-17. Review.

9. Barbosa ML, Rodrigues, HNS, Celino, SDM, Costa, GMC. Conhecimento de profissionais de enfermagem sobre o código de ética que rege a profissão. Rev baiana enferm. 2017;31(4):e21978.

10. Gil AC. Como elaborar projetos de pesquisa. 6a ed. São Paulo: Atlas; 2017. p. 45.

11. Grupo Prática Clínica: ciência e empreendedorismo. Pratica clínica: aceleramos ciência e tecnologia. Cálculo amostral [Internet]. Curitiba (PR): Grupo Prática Clínica; 2018 [citado em 20 de Junho de 2018]. Disponível em: https:// praticaclinica.com.br/anexos/ccolaborativa-calculo-amostral/ccolaborativa-calculo-amostral.php.

12. Brasil. Ministério da Saúde. Conselho Nacional de Saúde. Resolução CNS n. 466, de 12 de dezembro de 2012. Aprova diretrizes e normas regulamentadoras de pesquisas envolvendo seres humanos. [citado em 03 de Junho de 2020]. Disponível em: https://bvsms.saude.gov.br/bvs/saudelegis/cns/2013/ res0466 12 12 12 2012.html.

13. Conselho Federal de Enfermagem (COFEN). Pesquisa Perfil da Enfermagem no Brasil. Quadros resumos Brasil [Internet]. Brasília (DF): COFEN; 2013. [citado em 03 de Dezembro de 2018]. Disponível em: http://www.cofen.gov.br/perfilenfermagem/blocoBr/QUADRO\%2ORESUMO_Brasil_Final.pdf.

14. QUADROS, Alexander de et al. Desafios da Enfermagem Brasileira no Combate da COVID-19: uma reflexão. Enfermagem em Foco, [S.I.], v. 11, n. 1 Esp, ago. 2020. ISSN 2357-707X. Disponível em: <http://revista.cofen.gov.br/index.php/ enfermagem/article/view/3748/807>. Acesso em: 13 out. 2020. doi:https://doi. org/10.21675/2357-707X.2020.v11.n1 Esp.3748.
15. Pereira VA. Foto de funcionário só pode ser usada se houver autorização [Internet]. São Paulo: ConJur; 2006 [citado em 02 de Dezembro de 2019]. Disponível em: https://www.conjur.com.br/2006-jul-02/foto_funcionario_usada_autorizacao.

16. Conselho Federal de Enfermagem (COFEN). Resolução COFEN n. 554, de 17 de julho de 2017. Estabelece os critérios norteadores das práticas de uso e de comportamento dos profissionais de enfermagem, em meio de comunicação de massa: na mídia impressa, em peças publicitárias, de mobiliário urbano e nas mídias sociais[Internet]. Brasília (DF): COFEN; 2017 [citado em 02 de Dezembro de 2018]. Disponível em: http://www.cofen.gov.br/resolucao-cofen-no-05542017_53838.html.

17. Villas-Bôas ME. 0 direito-dever de sigilo na proteção ao paciente. Rev Bioét. 2015;23(3):513-23.

18. Martorell LB, Nascimento WF, Garrafa V. Redes sociais, privacidade, confidencialidade e ética: a exposição de imagens de pacientes no facebook. Interface (Botucatu). 2016;20(56):13-23.

19. Agência Nacional de Vigilância Sanitária (ANVISA). Gerência de Vigilância e Monitoramento em Serviços de Saúde (GVIMS). Gerência Geral de Tecnologia em Serviços de Saúde (GGTES). Implantação do núcleo de segurança do paciente em serviços de saúde: série segurança do paciente e qualidade em serviços de saúde [Internet]. Brasília (DF): ANVISA; 2016. [citado em 15 de Junho de 2020]. Disponível em: http://portal.anvisa.gov.br/documents/33852/3507912/ Caderno+6+-+Implanta\%C3\%A7\%C3\%A30+do+N\%C3\%BAcleo+de+Seguran $\% \mathrm{C} 3 \% \mathrm{~A} 7 \mathrm{a}+\mathrm{do}+$ Paciente+em+Servi $\% \mathrm{C} 3 \% \mathrm{~A} 7 \mathrm{os}+\mathrm{de}+\mathrm{Sa} \% \mathrm{C} 3 \% \mathrm{BAde} /$ cb237a40-ffd1-401f-b7fd-7371e495755c.

20. Souza MJ, Real DS, Cunha IC, Bohomol E. Práticas seguras para administração de medicamentos: construção e validação de instrumento. Enferm Foco. 2017;8(4):20-5.

19. Conselho Federal de Enfermagem (COFEN). Resolução COFEN n. 545, de 9 de maio de 2017. Atualiza a norma que dispõe sobre a forma de anotação e o uso do número de inscrição pelos profissionais de enfermagem[Internet]. Brasília (DF): COFEN; 2017 [citado em 02 de Dezembro de 2018]. Disponível em: http:// www.cofen.gov.br/resolucao-cofen-no-05452017_52030.html.

21. Goldim JR. Bioética: origens e complexidade. Rev HCPA. 2006;26(2):86-92.

22. Vasconcelos EV, Santana ME, Silva SE. Desafios da enfermagem nos cuidados paliativos: revisão integrativa. Enferm Foco. 2012;3(3):127-30. Revisão. 23. Organização Mundial de Saúde (OMS). 2002. [citado em 17 de Julho de 2020]. Disponível em: https://www.who.int/cancer/palliative/definition/en/ 24. Carvalho RT de. Parsons HA. Manual de Cuidados Paliativos ANCP Ampliado e atualizado $2^{\text {a }}$ edição. 2012 [citado em 17 de Julho de 2020]. Disponível em: http://formsus.datasus.gov.br/novoimgarq/24326/4052575_345331.pdf 25. Lysakowski S, Menin GE. Utilização de simulação clínica no ensino sobre terminalidade da vida na enfermagem: relato de experiência. Rev Docência Ens Sup. 2019;9:e002559.

26. Jekel JF, Elmore JG, Katz DL. Análise bivariada. In: Jekel JF, Elmore JG, Katz DL, editores. Epidemiologia, bioestatística e medicina preventiva. $2^{\mathrm{a}}$ ed. Porto Alegre: Artmed; 1999.p.85-94. 